\title{
New proposals for diagnosis and treatment of the chronic period without demonstrable pathology of Chagas disease
}

\section{Abstract}

Chagas disease goes through two stages, one is acute and the other chronic. Both the acute and chronic periods with pathology have treatment the chronic period without demonstrable pathology integrates the most important group, developing the disease only 25 to $30 \%$. We consider it essential to systematically monitor these patients with diagnostic and therapeutic tools appropriate to current cardiology
Volume II Issue 6 - 2018

Gimenez L, Mitelman J

Faculty, Department of Medicine, Spain

Correspondence: Gimenez L, Faculty, Department of

Medicine, Spain, Email jorgemitejman@yahoo.com.ar

\section{Introduction}

Pathophysiology Intervening factors in the development of cardiomyopathy

1. Intrensic myocardial damage during the acute and chronic phase because of:
a) Direct parasitic action.
b) Immunological disturbances.
c) Neurological damage.

2. Induced disorders due to the host immune response.

3. Alterations in the automatic nervous system.

4. Microvascular lesions with alterations in the microcirculation and subsequent myocytolysis. ${ }^{1}$

Our research group proposes a score of clinical outcomes, with validated studies and proposed treatment for subclinical lesions (autonomic, endothelial anatomical) early to prevent the development of Chagas cardiomyopathy. Integrated Score is to detect early alterations that would lead to the development of cardiac complications in chronic patients without proven pathology.

\section{Risk analysis}

With the approach of the disease using tools and diagnostic tests sufficiently validated and according to the association between them, it is determined to follow up the most committed patients and use different therapies according to the damage found. It is important to note that other studies may be used to detect subclinical lesions that have the same kind of recommendation and the same level of evidence used in this score. We believe that the persistence of the parasite in the infected organism would not be the only mechanism that would have a determinate role in the development of the pathogenesis of the illness and consequently even a successful etiological treatment would not be able to avoid the development of the terminal lesions characterized by the disease (Table 1). ${ }^{2,3}$

Table I Risk score (Mitelman-Gimenez)

\begin{tabular}{|c|c|c|c|}
\hline \multicolumn{4}{|l|}{ Risk score (Mitelman-Gimenez) } \\
\hline & Points & $\begin{array}{l}\text { Recommendations and } \\
\text { level of opinion }\end{array}$ & Treatment \\
\hline \multicolumn{4}{|l|}{ Exploration of the autonomic nervous system } \\
\hline Antimuscarinic receptor antibodies & 3 & IC & $\begin{array}{l}\text { Beta blockers and } \\
\text { Sympathomimetics }\end{array}$ \\
\hline Ergometry & 3 & IC & \\
\hline Ambulatory blood pressure monitoring: Non Dipper & 3 & Ila-B & \\
\hline Variability of cardiac frequency & 2 & IC & \\
\hline QT dispersion analysis & 2 & Ilb-C & \\
\hline \multicolumn{4}{|l|}{ Exploration of the endothelium } \\
\hline Soluble thrombomodulin or the von Willebrand factor & 3 & IC & Quinapril,Simvastatina \\
\hline Brachial echo Doppler & 3 & IC & \\
\hline
\end{tabular}


Table Continued....

\begin{tabular}{llll}
\hline Risk score (Mitelman-Gimenez) & Points & $\begin{array}{l}\text { Recommendations and } \\
\text { level of opinion }\end{array}$ & Treatment \\
\hline Evaluation of the autonomic myocardial substrate & & IC & Lisinopril-Losartan \\
Two-dimensional echocardiogram-tissue Doppler Imaging & 4 & 2 & III-B \\
Signal averaged electrocardiogram & 3 & Ilb-C \\
\hline Fibrosis markers & & & \\
\hline
\end{tabular}

Risk Score: Mild, I-9; Moderate, I0- I8; Risk score Severe, 19-23

This risk analysis allows

i. Addressing the disease with different tools and strategies.

ii. Classify patients according to their exposure is low or high, the latter being those that enhance the different variables.

iii. Establish diagnostic criteria and clinical implications.

iv. Make clinical decisions according to the identification of poor prognosis markers.

v. Use new therapeutic strategies. It is important to point out that other studies, beyond the conventional ones, can be used to detect subclinical lesions with the idea that they have the same kind of recommendation and the same level of evidence as that used in this score.

It is known that the parasite plays a causal role in the development of heart disease but the evidence that parasiticide medication prevents progression continues to be a fragile criterion and that the treatment of subclinical endothelial, microvascular and dysautonomic lesions with other measures must be addressed. Therapeutic Serological cure does not indicate clinical cure. ${ }^{4}$

\section{Acknowledgments}

None.

\section{Conflicts of interest}

Author declares that there is no conflict of interest.

\section{References}

1. Mitelman J, Giménez L, Diaz A, et al. Association between endothelial dysfunction assessed by ischemic test with brachial echo-Doppler and Von Willebrand factor in Chagas disease. Rev Arg de Cardiol. 2001;69:275-278.

2. Gimenez L, Mitelman J, Gonzalez C. Antiautonomic receptor antibodies, heart rate variability and arrhythmias in patients with Chagas disease. Rev Argent de Cardiol. 2003;71:109-113.

3. Mitelman J, Giménez L, et al. Non invasive diagnostic methods for detection of functional anomalies in chronic Chagas disease. Rev Argent de Cardiol. 2000;68:797-802.

4. Mitelman J, Giménez L, González C. Valorar la asociación de pruebas diagnósticas incruentas para la detección de alteraciones funcionales miocárdicas autonómicas y endoteliales en la enfermedad de chagas. Rev Guatemaltec de Cardiol. 2013;23:16-20. 